\title{
Evaluation of three different regional anesthetic techniques in postoperative pain control after inguinal hernia repair operations in adults patients
}

\section{Ghada A.Mohamed ${ }^{\text {a }}$, Osama H.Salman ${ }^{\text {, }}$ Ahmed Y. Abdelzaher ${ }^{\mathrm{a}}$}

${ }^{a}$ Anesthesiology, Intensive Care Medicine and pain management department, Qena University Hospital, South Valley University,Qena, Egypt .

Background: Various analgesic modalities have been used for postoperative analgesia in patients undergoing inguinal hernia surgery.In this randomized clinical trial, we have compared the analgesic efficacy of transverses abdominis plane (TAP) block with that of ilioinguinal/ iliohypogastric (II-IH) nerve block and quadrates lamborum(QL) block in patients undergoing unilateral open inguinal hernia repair.

Objectives: comparison of the efficacy of either of the three types of regional anesthetic blocks , the ultrasound -guided TAP block, ultrasound-guided Quadratus Lamborum block and ultrasound- guided ilioinguinal and iliohypogastric nerve block in quality and duration of postoperative pain control.

Patients and methods:This is a cross-sectional, hospital based study carried out on 90 cases undergoing inguinal hernia repair under general anesthesia using either of the three types of block in each group; the ultrasound-guided TAP block, ultrasound- guided ilioinguinal and iliohypogastric nerve block and ultrasound-guided Quadratus Lamborum block nerve All cases enrolled fromgeneralsurgerydepartment and seen at the pre operative holding area before going to the operative theatre of Qena university hospital between August 2018 to August 2019 .

Result(s):VAS were lower in the IINB group and QLB group compared to the TAP block group both at rest and during cough. The difference in VS score was statistically significant various times postoperative. Time to first analgesic request was delayed in IIIH nerve block $\operatorname{Group}(7.3 \pm 1.3)$ hours than TAP block group (5.9 \pm 1.3 )hours ( $\mathrm{P}$ value .008)and time to first analgesic request was delayed in QL block Group $(10.3 \pm 3.9)$ hours than TAP block group $(5.9 \pm 1.3)$ hours $(\mathrm{P}$ value 0.001$) .15$ patients $(50 \%)$ in TAP block group, 10 patient (33.3\%) in IINB group and 4 patients (13.3\%)required morphine 24 hours postoperative .

Conclusion:This study demonstrated that compared to TAP block II-IH nerve block and QL block provides better pain control after open repair of inguinal hernia when all blocks were administered under US guidance.

Keywords:US-guided nerve block, TAP, II-IH,QL, inguinal hernia surgery.

\section{Introduction:}

The International Association for the Study of Pain (IASP) defined pain as an unpleasant sensory and emotional experience associated with actual or potential tissue damage (Lovich et al., 2015).Excessive postoperative pain and the physiological stress response can influence postoperative outcomes, length of hospital stay, and overall costs of hospital care (Myles et al., 2002).

Around the world, inguinal hernia repair is one of the most frequent surgical interventions and is associated with moderate to severe postoperative pain. One of the most common
Several analgesic modalities have been used to treat postoperative pain, the mainstay of which is administration of parenteral or oral opioids. However, the systemic use of these analgesic medications is associated with an extensive side effect profile. As a result, there is an ongoing interest in developing regional anesthetic techniques that may reduce or eliminate the useof opioid analgesics after minor surgical procedures such ashernia repair.is associated with an extensive side effect as nausea and vomiting and respiratory depression(Joshi et al., 2012). Regional nerve block techniques offer a 
greatdegree of post-operative pain relief thus facilitatingearly ambulation and discharge. TAP block ,Ilioinguinal and iliohypogastric (II-IH) nerve blocks and QL block are among the most frequently used regional blocks performedfor analgesia following inguinal surgery and havebeen shown to significantly reduce pain associated with herniorrhaphy (Öksüz et al, 2017).

Tansversus Abdominis Plane block TAP is a local anaesthetic block used to provide analgesia to Anterior and Lateral abdominal wall, there is a promising dataemerging on the efficacy Of this block as postoperative analgesia in the Post abdominal wall surgery and represents part of Multimodal regimen inpost- operative analgesia (Hebbard and Fujiwaraet al, 2007).

Ilioinguinal and iliohypogastric (II-IH) nerve blocks are among the most frequently used regional blocks performedfor analgesia following inguinal surgery and have been shown to significantly reduce pain associated with herniorrhaphy (Toivonen et al., 2001).

TAPblock provides effective somatic analgesia with minimal orno visceral blockade. The need for visceral blockade toprovide better postoperative pain relief led to a more posteriorapproach that involves injecting the local anestheticintoa potential space posterior to the abdominal wall muscles and lateral to the quadrates lamborum muscle (QL) muscle (Visoiuet al., 2013).QLB aims to infiltrate local anesthetic into a facial plane that can reach the paravertebral space by dissecting the space behind the quadratuslamborum muscle.

\section{Subjects and Methods:}

This is a cross-sectional, hospital based study carried out on 90 cases undergoing unilateral inguinal hernia repair under general anesthesia using either the three types of block in each group the ultrasound -guided TAP block (control group), ultrasound-guided ilioinguinal and iliohypogastric nerve block and ultrasoundguided Quadratus Lamborum block nerve,30 cases in each group.All cases enrolled fromgeneralsurgerydepartment and seen atthe pre operative holding area before going to the operative theatre of Qena university hospital between August 2018 to August 2019.
Informed written consents were obtained from all patients and the technique of regional anesthesia explained. Approval was obtained from theInstitutional Human Ethics committee.

Patient were included in the age groupbetween 18 and 70 years belonging to the American Society of Anesthesiologists (ASA) I, II or III, posted for unilateral openinguinal hernia surgery. Patients were excluded if they belonging to ASAIV,or if they had local infection at the site of injection.orbleeding disorder ordrug allergies, bleeding tendency, bilateral inguinal hernia.

In the operating room all patients will be connected to the monitor including non, invasive blood pressure, and pulse oximeter.

An intravenous cannula was inserted and lactated Ringer's solution was infused at $20 \mathrm{ml} / \mathrm{kg}$ prior to start of the technique.

start the operation using general anaesthesia by $100 \mathrm{mcg}$ fentanyl, $(2 \mathrm{mg} / \mathrm{kg})$ propofol , and operation maintained by 1.5 MAC isofluraine without neuromuscular block, the airway is maintained by laryngeal mask.

The first technique; transverses abdominis plane block, the abdominal wall will be scanned by ultrasound as the probe will be placed anteriolateral part of abdominal wall between the iliac crest and the subcostalmargin, to obtain a transverse view of three layers of lateral abdominal wall respectively from superficial to downwards; the external oblique, internal oblique and transverses abdominis, the target injection site will be the plane between the aponeurosis of internal oblique and transverses abdominis muscle, $1 \mathrm{ml}$ of saline $(0.9 \%)$ will be injected to optimize the tip of the needle, then local anesthetic drug will be injected The injected solution will appear as a hypoechoic or dark area between the fascial layers. The remaining volume of local anesthetic is injected, and further hydrodissection of the fascial layers can be appreciated withultrasonography, with intermittent aspiration to confirm the needle site .

The second technique; ilioinguinal and iliohypogastricblock, the ultrasound transducer is placed perpendicular to the skin approximately 2 $\mathrm{cm}$ superior and $2 \mathrm{~cm}$ medial to the anterior superior iliac spine. The external oblique, internal 
oblique, and transverses abdominis muscles are identified. The needle is inserted medial to the transducer and advanced in plane using a medial to lateral direction until the needle tip reaches the TAP and local anestheticis deposited.

The third technique; quadrates lamborum type (QL) block, position the patient in the lateral decubitus with the side to be blocked uppermost and slightly flex the hip and knee joint, place a pillow under the head and a pillow below the lower flank to facilitate visualization of $\mathrm{QL}$ muscle, the ultrasound probe will be placed transverse over the flank in the posterior axillary line immediately cranial to the iliac crest, then the transducer will be slightly move posterior and angled caudally until the QL muscle is visualized at the level of L4 transverse process, the needle tip is advanced and targeted deep to the aponeurosis and superficial to the transversalis fascia, at the lateral margin og QL muscle.

Demographic data consisting of age, sex, weight, heightand body mass index were recorded. Haemodynamicparameters such as non-invasive blood pressureand heart rate were monitored and recorded beforeinduction, before administering the block, before theincision and after the incision. They were recordedintra-operatively at an interval of $10 \mathrm{~min}$ up to the end of operation, any complications, if presentwere recorded in addition to duration of the surgery.

The patients were interviewed at $0,2,4,6,8,12,18$ , and $24 \mathrm{~h}$ after surgery. VAS scores at rest and at cough, duration after which first analgesic was demanded by the patient,total analgesic consumption in the $24 \mathrm{~h}$ postoperative and the number of patients complain of nausea and vomiting.

\section{Results:}

Table(1)Showing the demographic data of studied group. (Group A) was aged from 22 years to 68 years and BMI ranged from 24.8 to 26.8 with operative time ranged from 50 minutes to 80 minutes, (Group B) was aged from 18 years to 68 years and BMI ranged from 22.5 to 26.2 and operative time ranged from 50 minutes to 80
minutes,(Group C)was aged from 19 years to 67 years with BMI ranged from 24.5to 26.3.

Table (1)Sociodemographic data of studied groups

\begin{tabular}{|l|l|l|l|l|}
\hline $\begin{array}{l}\text { Variab } \\
\text { le }\end{array}$ & Group A & Group B & Group C & $\begin{array}{l}\text { P } \\
\text { valu } \\
\text { e }\end{array}$ \\
\hline Age & $\begin{array}{l}4 \pm 12.8 \\
(22-68)\end{array}$ & $\begin{array}{l}4.4 \pm 15.5 \\
(18-68)\end{array}$ & $\begin{array}{l}41.5 \pm 15 . \\
6(19-67)\end{array}$ & 0.7 \\
\hline BMI & $25.9 \pm .6$ & $25.4 \pm 1.3$ & $25.5 \pm .6$ & 0.06 \\
\hline $\begin{array}{l}\text { Operat } \\
\text { ive } \\
\text { time }\end{array}$ & $62.8 \pm 8.9$ & $64.3 \pm 12$. & $63.7 \pm 7.6$ & 0.8 \\
\hline
\end{tabular}

P-value $<0.05$ is statistically significant

Table(2)and Figure(1): Showing the VAS scale 8during rest 24 hours post operative, the mean visual analogue scale is non statistically significant decreased in group B compared to group A ( $\mathrm{P}$ value .2), the mean visual analogue scale is statistically significant decreased in group $\mathrm{C}$ compared to group A ( $\mathrm{P}$ value .001 ). The mean visual analogue scale is statistically significant decreased in group B compared to group A in $4,6,8,12,18,24$ hours, the mean visual analogue scale is statistically significant decreased in group C compared to group A in 4,6,8,12,18,24 hours post operative.

Table (2)Comparison between the three studied groups regarding to visual analogue scale 24 hours post operative during rest

\begin{tabular}{|l|l|l|l|l|l|}
\hline Variable & $\begin{array}{c}\text { Group } \\
\text { A }\end{array}$ & $\begin{array}{c}\text { Group } \\
\text { B }\end{array}$ & $\begin{array}{c}\text { Group } \\
\text { C }\end{array}$ & $\begin{array}{c}\text { P } \\
\text { value } \\
\text { A\&B }\end{array}$ & $\begin{array}{c}\text { P } \\
\text { value } \\
\text { A\&C }\end{array}$ \\
\hline VAS 2 & $3.4 \pm .5$ & $3.2 \pm .5$ & $2.9 \pm .3$ & 0.2 & .001 \\
\hline VAS 4 & $2.9 \pm .6$ & $2.8 \pm .5$ & $2.3 \pm .5$ & .04 & $<.001$ \\
\hline VAS 6 & $2.9 \pm .5$ & $2.9 \pm .3$ & $2.2 \pm .4$ & .09 & $<.001$ \\
\hline VAS 8 & $3.2 \pm .8$ & $2.8 \pm .4$ & $2.3 \pm .8$ & .03 & $<.001$ \\
\hline VAS 12 & $2.4 \pm .5$ & $2.1 \pm .4$ & $1.9 \pm .6$ & .03 & .001 \\
\hline VAS 18 & $2 \pm .2$ & $1.9 \pm .3$ & $1.3 \pm .5$ & .04 & .001 \\
\hline VAS 24 & $1.6 \pm .5$ & $1.4 \pm .5$ & $1 \pm .00$ & .01 & .001 \\
\hline
\end{tabular}

P-value $<0.05$ is statistically significant 


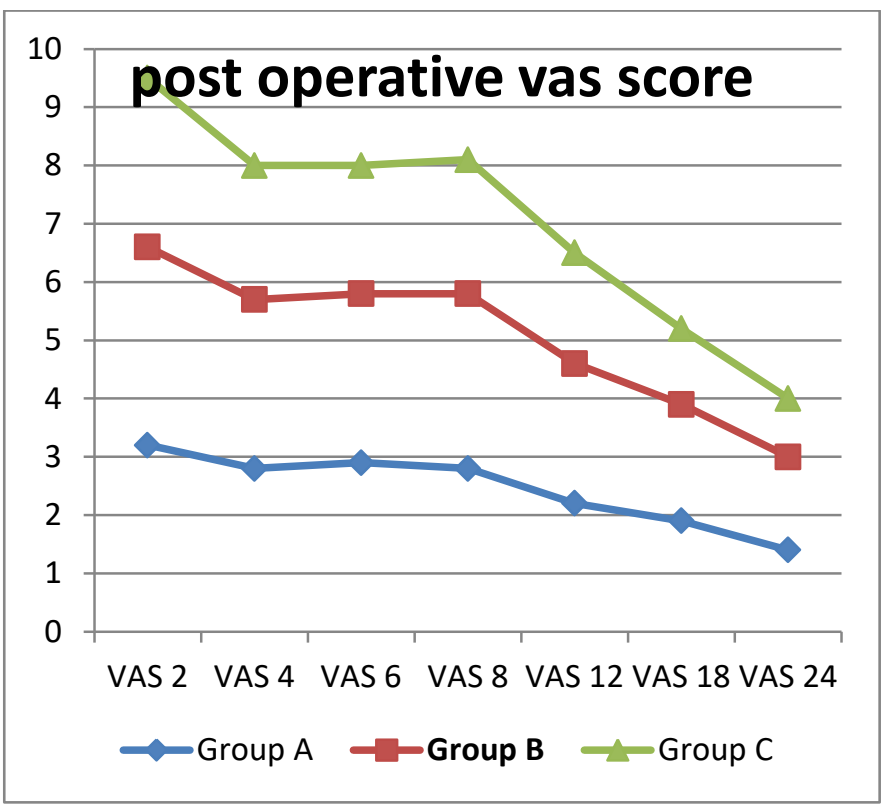

Figure(1) comparison between three groups regarding to visual analogue scale changes

Table(3) Showing the VAS scale during cough 24 hours post operative, the meanVAS scale during cough in group b and group c lower than the control group at varoius time interval.

Table(3) Comparison between the three studied groups regarding to visual analogue scale 24 hours post operative during cough

\begin{tabular}{|l|l|l|l|l|l|}
\hline $\begin{array}{l}\text { Variabl } \\
\text { e }\end{array}$ & $\begin{array}{l}\text { Group } \\
\text { p B }\end{array}$ & $\begin{array}{l}\text { Grou } \\
\text { p C }\end{array}$ & $\begin{array}{l}\text { P } \\
\text { valu } \\
\text { e } \\
\text { A\& } \\
\text { B }\end{array}$ & $\begin{array}{l}\text { Palue } \\
\text { A\&C }\end{array}$ \\
\hline $\begin{array}{l}\text { VAS } \\
\text { cough 2 }\end{array}$ & $3.6 \pm .9$ & $\begin{array}{l}3.5 \pm . \\
8\end{array}$ & $\begin{array}{l}3.1 \pm . \\
3\end{array}$ & 0.6 & .006 \\
\hline $\begin{array}{l}\text { VAS } \\
\text { cough 4 }\end{array}$ & $3.2 \pm .4$ & $3 \pm .2$ & $3 \pm .2$ & .04 & .005 \\
\hline $\begin{array}{l}\text { VAS } \\
\text { cough 6 }\end{array}$ & $3.1 \pm .4$ & $\begin{array}{l}3.1 \pm . \\
3\end{array}$ & $\begin{array}{l}2.8 \pm . \\
9\end{array}$ & 0.9 & .09 \\
\hline $\begin{array}{l}\text { VAS } \\
\text { cough } 8\end{array}$ & $3.3 \pm .0$ & $3 \pm .2$ & $\begin{array}{l}2.5 \pm . \\
5\end{array}$ & .03 & $\begin{array}{l}<.00 \\
1\end{array}$ \\
\hline $\begin{array}{l}\text { VAS } \\
\text { cough } \\
12\end{array}$ & $3 \pm .00$ & $\begin{array}{l}2.9 \pm . \\
32.5 \pm .\end{array}$ & 6 & .04 & $\begin{array}{l}<.00 \\
1\end{array}$ \\
\hline $\begin{array}{l}\text { VAS } \\
\text { cough } \\
18\end{array}$ & $2.6 \pm .5$ & $\begin{array}{l}2.3 \pm . \\
5\end{array}$ & $\begin{array}{l}1.8 \pm . \\
4\end{array}$ & .01 & .001 \\
\hline $\begin{array}{l}\text { VAS } \\
\text { cough } \\
24\end{array}$ & $2.1 \pm .3$ & $\begin{array}{l}1.9 \pm . \\
3\end{array}$ & $\begin{array}{l}1.2 \pm . \\
4\end{array}$ & .06 & .001 \\
\hline
\end{tabular}

\section{P-value $<0.05$ is statistically significant}

Table(4) showComparison between three groups regarding to time to first analgesia need by hours, the mean time to first analgesia need is statistically significantly prolonged in group B (7.3 \pm 1.3$)$ compared to group $\mathrm{A}(5.9 \pm 1.3)$ (P value $.008)$, and the that is statistically significantly prolonged in group $\mathrm{C}(10.3 \pm 3.9)$ compared to group B $(5.9 \pm 1.3)(\mathrm{P}$ value $<.001)$.

It shows Comparison between three groups regarding the total post operative morphine use by $\mathrm{mg}$,there is statistically significantly decrease in the morphine consumption in group B 10 cases (33.3\%) compared to group A 15 cases $(50 \%)$ (P value 004), there is statistically significantly decrease in the morphine consumption in group $\mathrm{C}$ 4 cases $(13.3 \%)$ compared to group A 15 cases (50 $\%)$ (P value 005).

Table(4) Comparison between the three studied groups regarding to post operative analgesia

\begin{tabular}{|c|c|c|c|c|c|}
\hline Variable & $\begin{array}{c}\text { Grou } \\
\text { p A }\end{array}$ & $\begin{array}{c}\text { Grou } \\
\text { p B }\end{array}$ & $\begin{array}{c}\text { Grou } \\
\text { p C }\end{array}$ & $\begin{array}{c}\text { P } \\
\text { valu } \\
\text { e } \\
\text { A\& } \\
\text { B } \\
\end{array}$ & $\begin{array}{c}P \\
\text { value } \\
\text { A\&C }\end{array}$ \\
\hline $\begin{array}{l}\text { time to } \\
\text { first } \\
\text { analgesia } \\
\text { need by } \\
\text { hours }\end{array}$ & $\begin{array}{l}5.9 \pm 1 . \\
3\end{array}$ & $\begin{array}{l}7.3 \pm 1 . \\
3\end{array}$ & $\begin{array}{l}10.3 \pm \\
3.9\end{array}$ & $\begin{array}{l}0.00 \\
8\end{array}$ & $\begin{array}{l}<0.00 \\
1\end{array}$ \\
\hline $\begin{array}{l}\text { duration } \\
\text { of post } \\
\text { operative } \\
\text { analgesia } \\
\text { by hours }\end{array}$ & $\begin{array}{l}5.9 \pm 1 . \\
3\end{array}$ & $\begin{array}{l}7.3 \pm 1 . \\
3\end{array}$ & $\begin{array}{l}10.3 \pm \\
3.9\end{array}$ & $\begin{array}{l}0.00 \\
8\end{array}$ & $\begin{array}{l}<0.00 \\
1\end{array}$ \\
\hline $\begin{array}{l}\text { total post } \\
\text { operative } \\
\text { morphin } \\
\text { e by mg }\end{array}$ & $\begin{array}{l}15 \\
(50 \%)\end{array}$ & $\begin{array}{l}10 \\
(33.3 \\
\%)\end{array}$ & $\begin{array}{l}4 \\
(13 . \%)\end{array}$ & $\begin{array}{l}0.00 \\
4\end{array}$ & 0.005 \\
\hline
\end{tabular}

$P$-value $<0.05$ is statistically significant

\section{Discussion:}

Our data indicate that patients who receive a USguided IIN-IHN Blockhave significantly less VAS 
both at rest and cough than the patients who receive a US-guided TAP block 4,8,12,18,24 hours after an open repair of inguinal hernia ,but there is no statistically difference in visual analogue scale in IIN-IHN block and TAB block in the first 2 hours post operative.

We also demonstrate that patients who receive a US-guided QL Blockhave significantly less VAS both at rest andcoughand are overall more satisfied than the patientswho receive a US-guided TAP block hours after an open repair ofinguinal hernia.

Our results were consistent with (Stav et al., 2016)who reported that there were no differences between the TAP and ILI-IHG groups themselves. This finding indicates that both methods of USguided blocks produce significant post-op pain relief immediately after surgery, with no significant difference between the procedures .

Our results were consistent with (Seyedet al.,2019 ) who found that patients who received a USguided IINB have significantly less postoperative pain both at rest and movement and are overall more satisfied than the patients who received a US-guided TAP block after an open repair of inguinal hernia. In addition, $\mathrm{We}$ also note that more patients in the IINB group (20 patients) reported high satisfaction with the quality of their analgesia than the group of patients receiving TAP block (6 patients).

Our results were not consistent with(Petersen et al.,2016) who conducted a study on patients undergoing inguinal hernia repair and compared TAP block to ilioinguinal nerve block and to placebo for postoperative pain management. They demonstrated similar analgesic effects with either technique while both are superior to the placebo group. It should be noted that these investigators utilized US guidance exclusively for the placement of the TAP block while IINBs were performed blindly by the operating surgeons. It has been shown that US-guided techniques for placement of IINB are superior to the blind technique (Khedkar et al., 2015) (Farag et al., 2017).

Our results were consistent with (Öksüzet al., 2017) who compared both the blocks who underwent unilateral inguinal hernia repair. Patients who needed analgesia administration postoperatively, within the first $24 \mathrm{~h}$, was significantly lesser in the QL block group $(P<$ 0.05)compared to TAP block group .

Our data indicate that the time for first need analgesia is statistically significant delayed in IINIHN block group compared to TAP block group , and the total morphine consumption is significantly lower in IIN-IHN block group compared to TAP block group .

Our results were consistent with( Kamal et al., 2018)who reported that US-guided IL/IH block provides superior analgesia and less morphine consumption compared to TAP block .

We also demonstrate that found that the time for first need analgesia is statistically significant delayed in quadrates lamborum block group compared to TAP block group, and the total morphine consumption is significantly lower in quadrates lamborum block group compared to TAP block group.

Our data our results were consistent with (Ueshima et al., 2017) who reported that QL block offers better postoperative analgesia, longer time required for the first analgesic requirement and lesser morphine dose required than TAP block group in lower abdominal surgery.This is consistent with(Öksüz et al., 2017) , compared quadrates lamborum block and TAP block in children who underwent unilateral inguinal hernia repair and reported that Children who needed analgesia administration postoperatively, within 
the first $24 \mathrm{~h}$, was significantly lesser in the QL block group.

\section{Conclusion:}

We conclude that US-guided II-IH nerve block is superior to US-guided TAP block in providing analgesia after inguinal hernia repair in adult patients regarding to; the time for first rescue analgesia, late post operative VAS score was during rest and during cough but not immediately post operative VAS score. Also Ultrasound guided ilioinguinal and iliohypogastric nerve block reduces the postoperative analgesic consumption compared to ultrasound guided transverses abdominis plane block in patients.

We also conclude that US-guided quadrates lamborum block is significantly superior to USguided TAP block in providing analgesia after inguinal hernia repair in adult patients with significant less post operative morphine consumption postoperative, delay in the first rescue analgesia and significant less VAS score during rest and during cough in quadrates lamborum block group at all time 24 hours postoperative. The degree of patient satisfaction is greatly more in quadratus block group than TAP block group.

\section{References:}

Callesen $\mathbf{T}$, Bech $\mathbf{K}$, Nielsen $\mathbf{R}$,Andersen $\mathbf{J}$, Hesselfeldt P, Roikjaer O, et al.,(1998).Pain after groin hernia repair. Br J Surg., 85:1412-4.

\section{Hebbard P, Fujiwara Y, Shibata Y, Royse C.(2007).Ultrasound-guided transversusabdominis plane (TAP) block. Anaesthesia and Intensive Care,35:616-7.}

Joshi GP, Rawal N, Kehlet H, PROSPECT collaboration,Bonnet F, Camu F, Fischer HB, et al. Evidence-basedmanagement of postoperative pain in adults undergoing openinguinal hernia surgery. Br J Surg 2012;99:168-85.

Kamal K, Jain P, Bansal T, Ahlawat GA. (2018).Comparative study to evaluate ultrasoundguided transversusabdominis plane block versus ilioinguinaliliohypogastric nerve block for postoperative analgesia in adult patients undergoing inguinal hernia repair. Indian J Anaesth,;62:2927.

\section{Lovich-Sapola J, Smith CE, Brandt CP.} (2015).Postoperative pain control.SurgClin North Am., 95(2):301-318.

Myles PS, Hunt JO, Fletcher $\mathrm{H}$ et al., (2002).Remifentanil, fentanyl, and cardiac surgery: a double-blinded, randomized, controlled trial of costs andoutcomes. AnesthAnalg., 95(4):805-812.

Öksüz G, Bilal B, Gürkan Y,Urfalioğlu A, Arslan M, Gişi G et al., (2017).Quadratuslumborum block versus transversusabdominis plane block in children undergoing low abdominal surgery: A randomized controlled trial. RegAnesth Pain Med, 42:674-9.

Petersen PL, Mathiesen O, Stjernholm P, et al., (2013). The effect of transversusabdominis plane block or local anaesthetic infiltration in inguinal hernia repair: a randomised clinical trial. Eur J Anaesthesiol, 30(7): 415-421.

Stav A, Reytman L, Stav M-Y, TroitsaA,irshon M, Alfici R, Dudkiewicz M, Sternberg A.(2016).TransversusAbdominis Plane Versus Ilioinguinal and Iliohypogastric Nerve Blocks for Analgesia Following Open Inguinal Herniorrhaphy. Rambam Maimonides Med J,7 (3):e0021. doi:10.5041/RMMJ.10248.

Toivonen J, Permi J, RosenbergPH. (2001). Effect of preincisionalilioinguinal and iliohypogastric nerve block on postoperativeanalgesic requirement in 
day-surgery patientsundergoingherniorrhaphy under spinal anaesthesia. ActaAnaesthesiolScand, 45:603-7.

Ueshima H, Otake H, Lin

JA.(2017).Ultrasound-guided quadratuslamborum block: An updated review of anatomy and techniques. Biomed Res Int, 2017:2752876.

Visoiu M, Yakovleva N. (2013). Continuous postoperative analgesia via quadratuslumborum block - An alternative to transversusabdominis plane block. PaediatrAnaesth, 23:959-61. 